\title{
Using Short-Time Storage Potentials of Run-of- River Hydropower for Frequency Control
}

\author{
Bastian Hase \\ Arbeitsgruppe Regenerative Energien \\ Institut für Statik \\ Technische Universität Braunschweig \\ Braunschweig, Germany \\ b.hase@tu-bs.de
}

\author{
Christian Seidel \\ Arbeitsgruppe Regenerative Energien \\ Institut für Statik \\ Technische Universität Braunschweig \\ Braunschweig, Germany
}

\begin{abstract}
With a growing share of fluctuating renewable energies, such as wind and photovoltaics, predictable power generation capacities become more and more important. In parallel, the decarbonization of the energy sector calls for additional balancing energy technologies. We developed an operation strategy that enables run-of-river hydroelectric (ROR) plants to deliver both constant load and balancing energy at the same time. This becomes possible, because the upstream reservoir levels of most plants can, to a certain extent, be flexible, without making further impacts.
\end{abstract}

Keywords-run-off-river hydropower, short-term storage, control energy, frequency control, balancing services, Germany

\section{INTRODUCTION}

Apart from pumped hydro storage, most countries' production of balancing energy is highly based on fossil technologies. Yet, as reducing carbon footprints in the energy sector becomes more and more important, these capacities are often replaced by fluctuating renewable energies such as wind-power and photovoltaics [1]. This situation calls for additional emission free balancing energy technologies [2].

Run-of-river hydropower (ROR) is a very promising candidate to fill this technological gap. Currently, ROR hydroelectric plants are already used for negative automatic and manual frequency restoration reserve (aFRR and mFFR) [3]. However, when plants are operated at a quasi-constant upstream water level, power reductions due to the delivery of negative frequency restoration reserve almost necessarily lead to additional water losses over the attached weirs and thus to energy losses. Moreover, constant upstream water levels impede the delivery of frequency containment reserve (FCR) and positive frequency restoration reserve. This is because the abrupt increases of output power, coming along with the delivery of positive control power, almost necessarily cause a fall of the upstream reservoir level.

However, on many hydropower sites flexible upstream water levels within a limited band are technically possible and even ecologically desirable [4]. Recent studies showed, that a peak-to-peak amplitude of $30 \mathrm{~cm}$ is feasible on most rivers in Germany, including those used as waterways. Where this is impeded by minimum depths or vertical clearances, a continuous storage operation, using the reservoir of an upper hydroelectric plant as main storage can be implemented [5].

Flexible upstream reservoir levels of ROR-hydroelectric plants create significant short-time storage potentials, allowing a power production that is temporarily independent of the discharge to the reservoir. On the one hand, this enables hydropower stations to schedule their power production before the start of delivery and hold the power exactly constant during the delivery interval. Depending on the lead time and delivery time achieved with this storage, a station operated this way can play a similar role in the energy system as a fossil plant. On the other hand, the short time storages can be used to provide positive and negative control. Consequently, ROR-plants, making use of these potentials serve the energy system twice: By providing control energy and by exactly complying with to the production schedule.

\section{SIMULATION STRATEGY}

A combined operation mode with the supply of constant base power and all three types of control energy was simulated for the years 2015-2017. The simulations were conducted on a model of the hydroelectric plant in Bannetze-Hornbostel that is currently under construction on the Aller-river in northern Germany. The plant is projected to have a maximum power output of $700 \mathrm{~kW}$ and a maximum flow rate of $60 \frac{\mathrm{m}^{3}}{\mathrm{~s}}$. Instead of a turbine, it will be equipped with a high-performance waterwheel that is specially designed for high efficiencies at low heads. With a nominal head of only $1.4 \mathrm{~m}$, this technology allows to generate power down to a minimum head of $30 \mathrm{~cm}$. The peak-to-peak amplitude of the upstream reservoir is only $27 \mathrm{~cm}$. As upper and lower limits, the current lead operation levels during summer and winter of the existing weir were chosen [6]. For the first investigations in this paper the target upstream water level is set $10 \mathrm{~cm}$ below the maximum and 17 $\mathrm{cm}$ above the minimum level. TABLE I. shows the parameters used for the simulations.

In order to keep the influence of the hydro technology on the simulation results as low as possible, the plant's inertia was neglected. In this case, the upstream reservoir level is defined by the differential equation

$$
\dot{h}_{U}(t)=\frac{Q(t)}{A_{\text {res }}}-\frac{P_{B, i}+P_{C}(t)}{\left(h_{U}(t)-h_{D}(t)\right)} \cdot \frac{1}{A_{r e s} \cdot \rho \cdot g \cdot \eta}
$$

with

$$
\begin{array}{ll}
P_{B, i} & \text { base power of de } \\
\rho=1000 \frac{\mathrm{kg}}{\mathrm{m}^{3}} & \text { density of water }
\end{array}
$$


TABLE I. PARAMETERS USED FOR MODELLING THE HYDROELECTRIC PLANT IN BANNETZE-HORNBOSTEL

\begin{tabular}{|l|c|c|}
\hline \multicolumn{2}{|c|}{ Simulation parameters } \\
\hline \multicolumn{1}{|c|}{ Parameter } & Symbol & Value \\
\hline maximum power output & $P_{\max }$ & $700 \mathrm{~kW}$ \\
\hline maximum flow rate & $Q_{\max }$ & $60 \frac{\mathrm{m}^{3}}{\mathrm{~s}}$ \\
\hline efficiency (constant) & $\eta$ & $85 \%$ \\
\hline reservoir area & $A_{\text {res }}$ & $432,000 \mathrm{~m}^{2}$ \\
\hline max. upstream water level & $h_{U}^{\max }$ & $h_{U}^{\text {target }}+0.10 \mathrm{~m}$ \\
\hline min. upstream water level & $h_{U}^{\min }$ & $h_{U}^{\text {target }}-0.17 \mathrm{~m}$ \\
\hline mean head 2015-2017 at $h_{U}^{\max }$ & $H_{\text {nom }}$ & $1.79 \mathrm{~m}$ \\
\hline minimum head & $H_{\text {min }}$ & $0.30 \mathrm{~m}$ \\
\hline
\end{tabular}

$g=\frac{9,81 m}{s^{2}}$

gravitational constant.

When interpreting the hydro-plant as a dynamic control system, the three time variable values

- produced control energy $P_{C}(t)$ calculated from the national demand $P_{C, \text { Germany }}(t)$

- discharge into the reservoir $Q(t)$

- downstream water level $h_{D}(t)$

have the function of disturbance inputs, impeding the stabilization of the upstream water level. The produced control energy $P_{C}(t)$ and the discharge $Q(t)$ are available as 15minute-values, whereas the downstream reservoir level $h_{D}(t)$ has a daily resolution.

When considering the undisturbed system, these values are constant. In this case, the second derivative of the upstream reservoir level during a delivery interval of constant base power is defined as

$$
\ddot{h}_{U}(t)=\dot{h}_{U}(t) \cdot \frac{P_{B, i}+P_{C}}{\left(h_{U}(t)-h_{D}\right)^{2}} \cdot \frac{1}{A_{\text {res }} \cdot \rho \cdot g \cdot \eta}
$$

Since the two right factors $\frac{P_{B, i}+P_{C}}{\left(h_{U}(t)-h_{D}\right)^{2}}$ and $\frac{1}{A_{\text {res }} \cdot \rho \cdot g \cdot \eta}$ can never become negative, the condition

$$
\operatorname{sgn}\left(\ddot{h}_{U}\right)=\operatorname{sgn}\left(\dot{h}_{U}\right)
$$

is always valid. As a consequence, an initial increase/decrease of the upstream water level will keep growing/falling at an ever increasing speed. As soon as the maximum upstream water level is reached, the excessive water has to be spilled over the weirs. When reaching the minimum water level, however, the plant's output power has

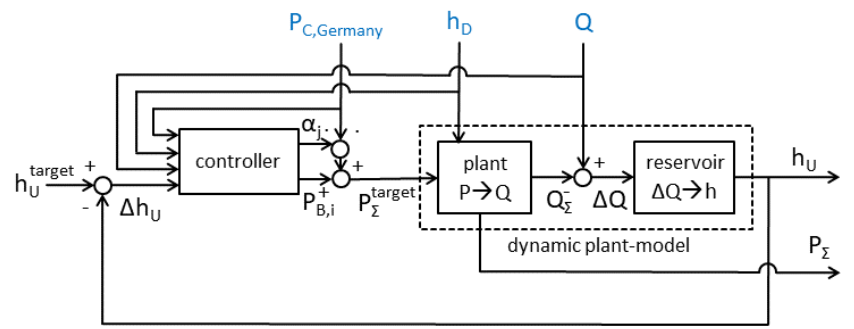

Fig. 1. Block diagram of the control loop to be reduced in order to prevent the reservoir level from falling any further. As a result, the scheduled power cannot be completely produced. Therefore, a controller is necessary to stabilize the reservoir level. Together, the controller and the plant model form a closed control loop. Apart from the stabilization of the water level, the controller has the task to calculate the maximum deliverable amount of control energy during a tendering interval. Consequently, the controller is responsible for the organization of the entire combined plant operation.

The stabilization of the upstream water level is achieved by adjusting the base power $P_{B, i}$ in regular time intervals. Therefore the control unit estimates the flow rate through the water wheel, necessary to bring the upstream water level back to the target value by the end of the next delivery interval. This flow rate is then used to calculate the scheduled base power for that interval. The base power $P_{B, i}$ is scheduled with a lead time $t_{L}$ and held constant during the length of the delivery interval $t_{D}$. Consequently, the time between the calculation of the correcting variable $P_{B, i}$ and it's effect on the system is

$$
t_{L} \leq \Delta t \leq t_{L}+t_{D}
$$

This is why a two-step calculation $P_{B, i}$ was implemented (Fig. 2). When the calculation is done at $t_{0}$, in the first step the controller estimates the upstream water level $h_{U}\left(t_{1}\right)$ at the start of the next delivery interval, based on current discharge and other system parameters. In the second step this water level is used to calculate the output power that is necessary to reach the lead value $h_{U}^{\text {target }}$ by the end of the delivery interval $t_{2}$.

The maximum marketed control power is determined according to the tender modalities shown in TABLE II. . These modalities were valid in August 2018. The calculation of the maximum marketed control energy is executed at the time of bidding for each tendering interval. When neglecting special regulations for public holidays etc., this is between 9 and 129 hours before the start of delivery, depending on the type of control energy.

In order to minimize the influence of the bidding strategy, in the simulation the activation of the control power capacities

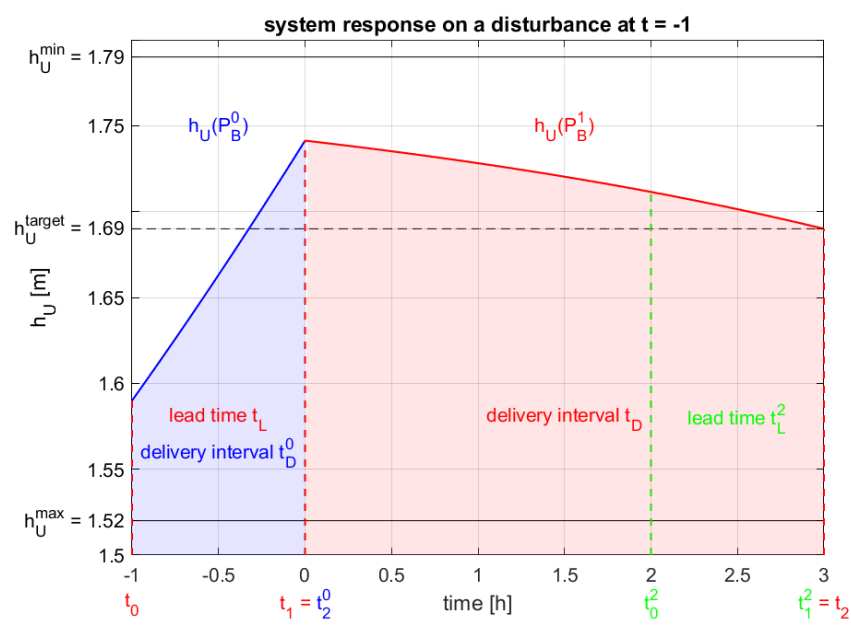

Fig. 2. Step response of the undisturbed system with a lead value of $h_{U}^{\text {target }}=1.69 \mathrm{~m}$ to an initial upstream water level of $h_{U}\left(t_{0}\right)=1.59 \mathrm{~m}$ and an unsufficient initial base power production. 
TABLE II. TENDER MODALITIES OF CONTROL ENERGY USED IN THE SIMULATION.

\begin{tabular}{|l|c|c|c|}
\hline \multirow{2}{*}{$\begin{array}{c}\text { Tender modalities } \\
\text { for control energy }\end{array}$} & \multicolumn{3}{|c|}{ Type of control energy } \\
\cline { 2 - 4 } & $\boldsymbol{F C R}$ & $\boldsymbol{a F R \boldsymbol { R }}$ & $\boldsymbol{m F R \boldsymbol { R }}$ \\
\hline \multirow{2}{*}{ delivery time } & weekly & daily & daily \\
\cline { 2 - 4 } & $168 \mathrm{~h}$ & $24 \mathrm{~h}$ & $24 \mathrm{~h}$ \\
\hline bidding deadline & Tu. $15: 00$ & $15: 00$ & $10: 00$ \\
\hline start of delivery & Mo. $0: 00$ & next day 0:00 & next day 0:00 \\
\hline lead time & $129 \mathrm{~h}$ & $9 \mathrm{~h}$ & $14 \mathrm{~h}$ \\
\hline
\end{tabular}

is not executed in the range of the lowest price offers. Instead it is assumed, that during each tender period $j$, all ROR-plants deliver the same constant share of $\alpha_{j}$ of the nationally activated balancing power. This proportion corresponds to the ratio of the control power awarded in the auction $P_{C j, p l a n t}^{\max }$ and the total amount of control power announced in the tender $P_{C j, G e r m a n y}^{\max }$ :

$$
\alpha_{j, \text { target }}=\frac{P_{C j, \text { plant }}^{\max }}{P_{C j, \text { Germany }}^{\text {max }}}=\frac{P_{C}(t)}{P_{C, \text { Germany }}(t)} .
$$

Consequently, the control power, that has to be delivered by the plant is

$$
P_{C, \text { target }}(t)=\left\{\begin{array}{cc}
\alpha_{j, \text { target }}^{+} \cdot P_{C, \text { Germany }}(t) & \text { for } P_{C, \text { Germany }}>0 \\
\alpha_{j, \text { target }}^{-} \cdot P_{C, \text { Germany }}(t) & \text { else }
\end{array} .\right.
$$

The amount of automatic and manual frequency restoration reserve, marketed by the plant in an upcoming tender round is determined by the controller in the form of the delivery factors $\alpha_{j, \text { target }}^{+}$and $\alpha_{j, \text { target }}^{-}$. These factors are calculated based on the plant's positive and negative power reserves, forecast by the controller. Due to the long delivery periods, the prediction accuracy is limited. Therefore, the forecast positive and negative power reserves are additionally multiplied by freely selectable marketing factors $0 \leq \kappa^{+} \leq$ 1,5 and $0 \leq \kappa^{-} \leq 1,5$.

$$
\begin{aligned}
\alpha_{j, \text { target }}^{+} & =\kappa^{+} \cdot \frac{P_{\text {res }, j}^{+}}{P_{C j, G e r m a n y}^{m a x+}} \\
\alpha_{j, \text { target }}^{-} & =\kappa^{-} \cdot \frac{P_{r e s, j}^{-}}{P_{C j, G \text { Germany }}^{m a x}}
\end{aligned}
$$

with

$$
\begin{aligned}
& P_{r e s, j}^{+}, P_{r e s, j}^{-} \begin{array}{l}
\text { minimum forecast positive and negative } \\
\text { power reserves during coming delivery }
\end{array} \\
& \text { interval } j
\end{aligned}
$$

Hence, this pair of marketing factors $\underline{\kappa}=\left(\kappa^{+} ; \kappa^{-}\right)$ determines the share of the predicted power reserves that shall be offered as control power in the upcoming auction. When $\kappa^{+}$or $\kappa^{-}$are equal to zero, no positive or negative control power is delivered at all. In change, at $\kappa>1$, the marketed control power is higher than the predicted power reserve. Consequently, the marketing factor allows a free adjustment of the amount and reliability of control energy, allowing to investigate the interaction between positive and negative frequency restoration reserve.
In case of frequency containment reserve, the positive and negative power components are marketed together. As a result a common delivery factor $\alpha_{j, \text { target }}=\alpha_{j, \text { target }}^{+}=\alpha_{j, \text { target }}^{-}$is used. It is calculated from the minimum of the predicted power reserves in positive and negative direction multiplied by the common marketing factor $\kappa$.

$$
\alpha_{j, \text { target }}=\kappa \cdot \frac{\min \left(P_{r e s, j}^{+}, P_{r e s, j}^{-}\right)}{\left.P_{C j, G e r m a n y}^{\max }\right)}
$$

\section{INFLUENCE OF BASE POWER LEAD TIME AND DELIVERY TIME}

In operation with constant base power, the amount and reliability of both, base power and control energy is significantly influenced by the ability of the controller to stabilize the upstream water levels. Therefore, the lead time and step time between the base power adjustments should not be too high. Fig. 3 shows the upstream water levels for different pairs $\left(t_{L} ; t_{D}\right)$ of lead time and delivery time during 4 exemplary days in 2016. In the simulations the downstream water levels were considered as constant and a marketing factor of $\underline{\kappa}=(0 ; 0)$ was chosen, equivalent to no delivery of control power. Consequently, the discharge to the reservoir $Q(t)$ is the only disturbance input in the system. In the figure $Q(t)$ is shown as a green line on the right axis.

The different pairs illustrate, that the quality of stabilizing the upstream water level clearly depends on the lead time and delivery time, which together sum up to the time between two adjustment steps. In case of the value pair $\left(t_{L}, t_{D}\right)=$ $(1 h, 3 h)$, represented by the black curve, the upstream water level can be maintained within $\pm 10 \mathrm{~cm}$ of the lead value $h_{U}^{\text {target }}$. Consequently, neither water must be drained over the weir, nor is the minimum allowed water level reached. If the sum of lead time and delivery time $t_{L}+t_{D}=t_{2}-t_{0}$ is increased, the stabilization of the upstream water level becomes more and more difficult. In the extreme case of the red curve with $\left(t_{L}, t_{D}\right)=(6 h, 12 h)$ the upstream water level permanently oscillates between the upper and lower limit. Reaching the maximum upstream water level results in additional water losses over the weir $\Delta W_{\text {weir }}$, which should be avoided from an efficiency point of view. However, this does

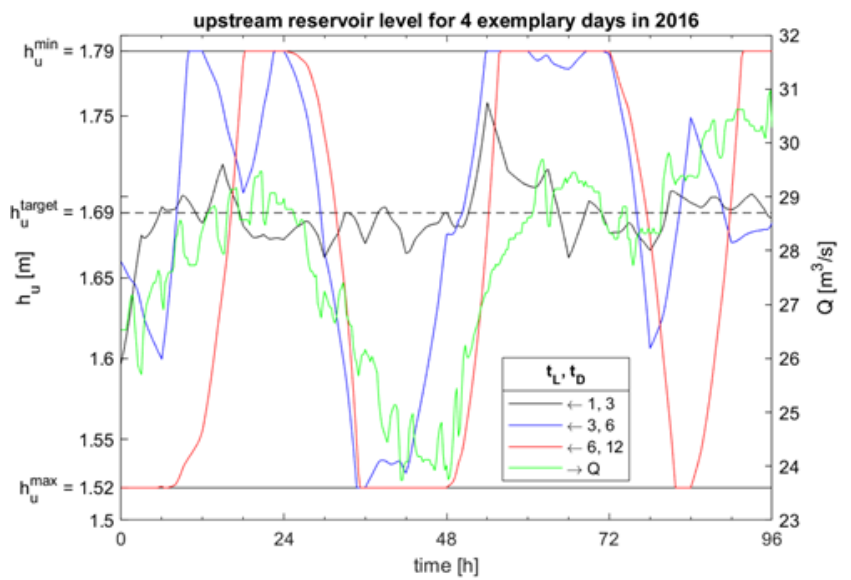

Fig. 3. Upstream water levels for different pairs of lead time $t_{L}$ and delivery time $t_{D}$ for the base power on the left axis and discharges to the reservoir on the right axis for an exemplary time period of four days in 2016. Other disturbance inputs are neglected. 
not imply the reliability of scheduled power deliveries. When the lower limit is reached and the plants' total power output must be reduced, the delivery of positive control energy and/or base power is directly affected. In this case, the resulting delivery failures directly reduce the reliability, which is defined as the quotient $R=\frac{W}{W_{\text {target }}}$ of actually delivered and projected energy within the time period considered. This reliability factor can be calculated for the base power as well as for the different types of control energy.

In Fig. $4 \mathrm{a}$ the reliability $R_{B}$ of the base power, kept constant during intervals $t_{D}$, is shown as a parameter field of $t_{L}$ and $t_{D}$ for 2016. Due to flooding periods water losses over the weir can generally not completely be avoided. However, the comparison with the water losses over the weir in conventional operation (i.e. with a quasi steady upstream water level and no control unit) is a good indicator for an imperfect stabilization of the upstream water level against the upper limit. Fig. 4b shows the additional water losses over the weir $w_{\text {weir }}=\frac{\Delta W_{\text {weir }}}{W_{\text {conv }}}$ compared to the energy generation in conventional operation mode $W_{\text {conv }}$. The three value pairs $\left(t_{L}, t_{D}\right)$ considered in Fig. 3 are marked in the parameter fields
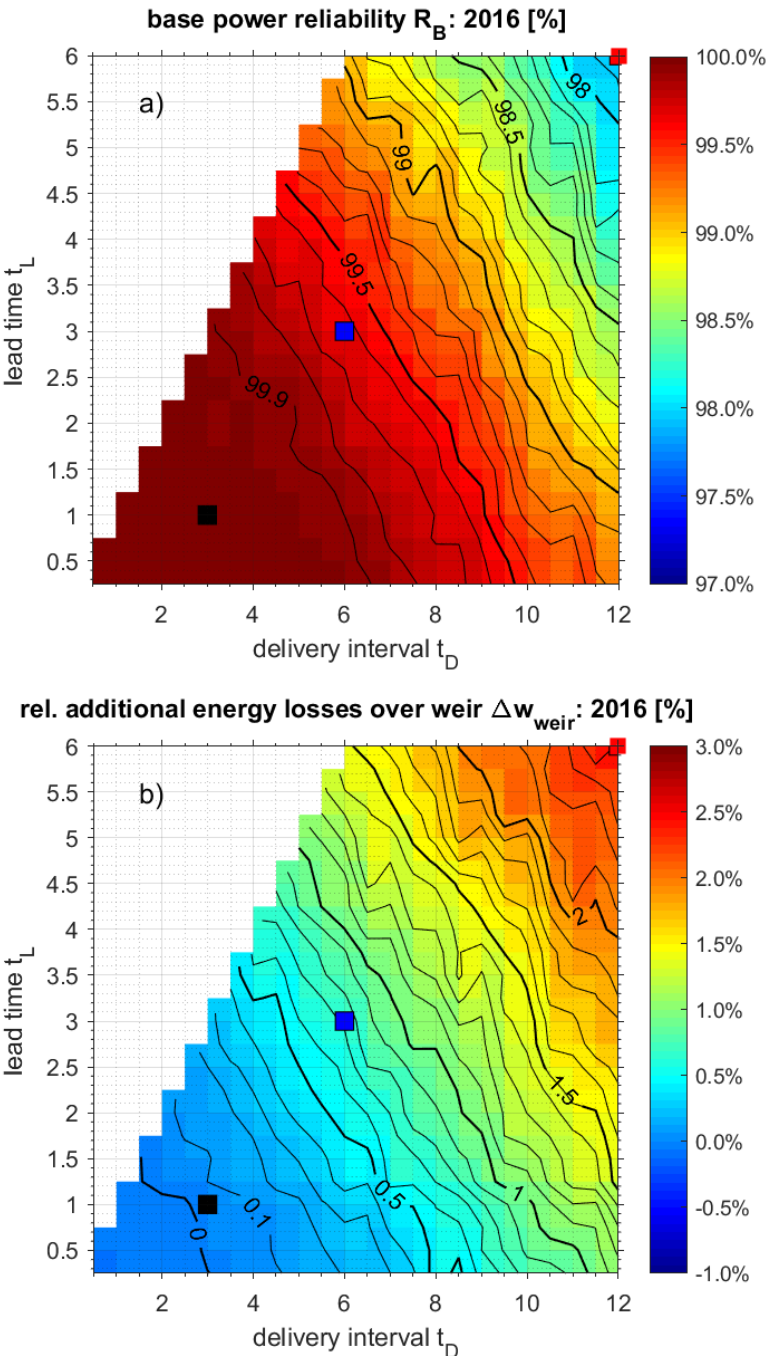

Fig. 4. a): Reliability of base power depending on lead time and time of constant delivery for a scenario without production of control energy in 2016. b): Energy losses over the weir, caused by the plant operation with constant base power as percentages of the energy production in conventional operation for a scenario without production of control energy in 2016. as squares with corresponding color. For the black scenario of $\left(t_{L}, t_{D}\right)=(1 \mathrm{~h}, 3 \mathrm{~h})$, a base power reliability of almost $100 \%$ is achieved. With $w_{\text {weir }}=0$, the weir losses are not higher than in conventional operation. When the lead time and delivery time are increased to $\left(t_{L}, t_{D}\right)=(3 h, 6 h)$, already an additional $0.7 \%$ of the energy generated in conventional operation is dissipated over the weir. This value increases to $2.4 \%$ at $\left(t_{L}, t_{D}\right)=(6 h, 12 h)$. At the same time, the reliability of the base power reduces to only $97.8 \%$.

Despite the jagged course of the black isolines caused by discrete calculation, a dependency of both, the base power reliability $R_{B}$ and the additional weir losses $w_{\text {weir }}$ from the sum of lead and delivery time $t_{L}+t_{D}$ is clearly noticeable

$$
f \approx f\left(t_{L}+t_{D}\right) \quad \text { for } f=\left\{R_{B}\left(t_{L}, t_{D}\right) ; w_{\text {weir }}\left(t_{L}, t_{D}\right)\right\} .
$$

This shows that these important values for the description of the controller quality strongly depend on the time between the calculation of $P_{B, i}$ and the end of its effect on the system $t_{L}+t_{D}$. The time interval $t_{D}$ between two consecutive control steps, in contrast, has only a minor influence on the control accuracy. Consequently, the duration of a delivery interval of constant base power could be increased/reduced without any change in reliability if the lead time between marketing and start of delivery is reduced/increased by the same time.

A good stabilization of the upstream water level in the system only disturbed by the flow rate $Q(t)$, is necessary, when the production of control energy and the time-variable downstream water level shall also be considered. For this reason, a delivery time of $t_{D}=3 \mathrm{~h}$ and a lead time of $t_{L}=$ $1 \mathrm{~h}$ are used for the further investigations.

\section{INFLUENCE OF THE LEAD VALUE FOR THE UPSTREAM WATER LEVEL}

In the previous considerations, the lead value of the upstream water level was chosen with $h_{U}^{\max }-h_{U}^{\text {target }}=$ $10 \mathrm{~cm}$, allowing to store and remove water at any time. This corresponds to a battery that is constantly kept at a charge state of around $60 \%$. The intention behind this approach is to allow the compensation of the disturbance inputs in both directions, namely the demand for control power and fluctuations in the discharge or underwater level. However, reaching the minimum upstream water level $h_{U}^{\min }$ is particularly critical, as the scheduled power cannot be delivered. Therefore increasing the lead-upstream level and accepting additional water losses over the weir can be useful to increase the reliability of the positive control energy.

For an assessment of the influence of the target upstream water level on the potentials of the plant's different energy products, it is necessary to consider both, the amount and reliability of the corresponding product. In order to convey a better understanding of the potentials, instead of annual work the deliverable balancing energy is expressed as an extrapolated delivery factor $\alpha$ :

$$
\alpha=\frac{W_{C}}{W_{C, \text { Germany }}} \cdot \frac{P_{\text {Germany }}}{P_{\max }}
$$

with

$$
\begin{array}{ll}
W_{C, \text { Germany }} & \text { national demand of control energy } \\
P_{\text {Germany }} & \text { national ROR-capacity }
\end{array}
$$


This theoretical value is equivalent to the share of the German control energy demand that can be covered by nonswelling ROR, when upscaling the potentials of the plant in Bannetze-Hornbostel by the total installed power capacity. The delivery factor $\alpha$ and the reliability $R$ usually refer to the entire delivery period considered (i.e. generally 1 or 3 years). Therefore, these mean values are sometimes exceeded and sometimes fallen short of. Next to these parameters for the control energy, the annual production of base energy $W_{B}$ and the total energy produced by the plant $W_{\Sigma}$ are also important for judging the potentials. These two values are connected via the balance of generated control energy $W_{C}^{+}+W_{C}^{-}$:

$$
W_{\Sigma}=W_{B}+W_{C}^{+}+W_{C}^{-}
$$

For a better illustration, these values are related to the energy harvest during conventional operation:

$$
w_{\Sigma}=\frac{W_{\Sigma}}{W_{\text {conv }}}
$$

and

$$
w_{B}=\frac{W_{B}}{W_{\text {conv }}}
$$

The influence of the target upstream water level on the base power and control energy potentials can be seen particularly well, when high amounts of control power are produced. Fig. 5 shows the most important parameters for the generation of automatic frequency restoration reserve at the maximum marketing factors $\underline{\kappa}=(1.5 ; 1.5)$ during the years 2015-2017. Both the delivery factor $\alpha^{+}$and the reliability $R^{+}$ of the positive control energy clearly show an optimum at the highest possible target upstream water level. Surprisingly the plant's total energy production $W_{\Sigma}$ also increases as $h_{U}^{\text {target }}$ is raised, even though more water has to be drained over the weir. This is due to the fact that the increasing average head overcompensates the additional weir losses $\Delta W_{\text {weir }}$.

The amount and reliability of the negative control energy and base power are largely indifferent to the target level of the upstream reservoir. Consequently, it can be summarized that

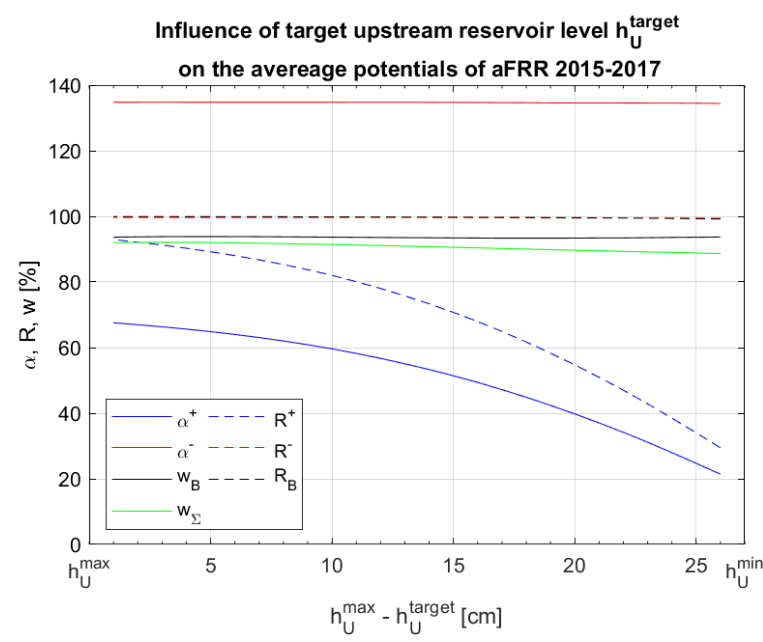

Fig. 5. Delivered amounts and reliabilities of positive and negative automatic frequency restoration reserve, base power and total energy production, depending on the target upstream water level for a marketing factor of $\kappa=(1.5 ; 1.5)$ in the years $2015-2017$. a high reserve for lowering the water level largely increases the control energy potentials, whereas the possible range for raising the water level has no big effect.

In order to achieve maximum control energy-potentials, the target value for the upstream reservoir level should therefore be chosen as close as possible to the maximum water level. However, this does not necessarily lead to a maximum total energy production $W_{\Sigma}$. For two upstream water levels $h_{\text {target }}^{2}>h_{\text {target }}^{1}$, this is only the case, when the condition

$$
\left(\frac{h_{\text {target }}^{2}-h_{\text {target }}^{1}}{H_{\text {nom }}}\right)>\frac{\int Q_{W}^{2}-Q_{W}^{1} d t}{\int Q d t} \Leftrightarrow W_{\Sigma}^{2}>W_{\Sigma}^{1}
$$

with $Q_{W}$ as the water drain over the weir, is fulfilled. This relation shows, that the energetic compensation of the increasing weir losses at $h_{\text {target }}^{2}$ by rising heads gets less, the higher the nominal head of the plant $H_{\text {nom }}$ is.

\section{CONTROL ENERGY POTENTIALS}

Since the maximum control energy potentials can be achieved, when the upstream reservoir level is maintained as high as possible, for the further investigations a lead value $h_{U}^{\text {max }}-h_{U}^{\text {target }}=2 \mathrm{~cm}$ is used. This target allows a temporal lowering of the reservoir level of $25 \mathrm{~cm}$, before the minimum value is reached.

Fig. 6 shows the average achievable delivery factor $\alpha(\kappa)$ and corresponding reliability $R(\kappa)$ of the frequency containment reserve over the marketing factor $\kappa$ for the years 2015-2017. The dashed lines break these two values further down to the positive and the negative power component. When extrapolating the potentials to the whole German RORcapacity, a three-year average of more than $150 \%$ of the national demand can be covered. However, the coverage and reliability is generally higher for the negative power component than for the positive. Besides, especially for the positive power component, higher coverages $\alpha^{+}$lead to lower reliabilities $R^{+}$. In order to cover an average of $100 \%$ of the national demand for both power components, a marketing factor of $\kappa=0,97$ is necessary. This leads to an overall reliability of $95 \%$, meaning that $95 \%$ of the marketed control

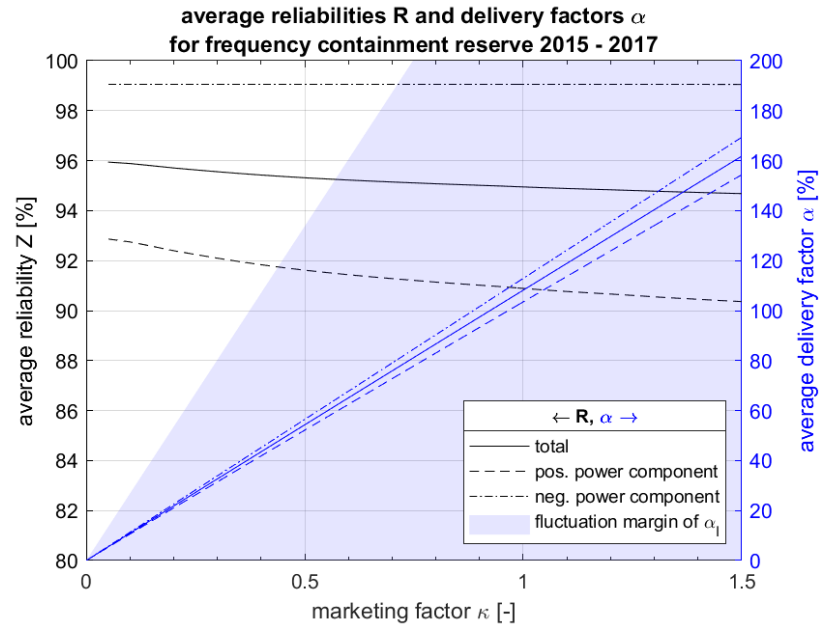

Fig. 6. Average reliability $R(\kappa)$ and achievable shares of the national demand $\alpha(\kappa)$ of frequency containment reserve over the marketing factor $\kappa$ during the years 2015-2017. The values are further broken down to the positive and negative component of the FCR-demand. The blue area shows the spread of $\alpha_{j}(\kappa)$ during the different one-week delivery intervals. 
energy can actually be delivered when demanded. As a consequence, a remaining 5\% gap has to be covered by backup capacities, of which around $91 \%$ are required for backing up the positive power component and only $9 \%$ are needed for the negative power component.

Due seasonal and climatic influences, the delivery factors $\alpha_{j}(\kappa)$ achieved during the 1 -week delivery intervals of the frequency containment reserve can strongly deviate from the three-year mean value $\alpha(\kappa)$. Therefore, in Fig. 6 the range of $\alpha_{j}(\kappa)$ is highlighted in blue. At peak times, around 2.5 times of the average value can be supplied, while no control power at all is delivered during flooding events. Thus, it can be summarized, that the German ROR-hydropower can provide a considerable share of the national demand for frequency containment reserve in a climate-neutral manner. However, many rivers show similar seasonal flow characteristics in the course of one year. This bears a certain risk that FCRpotentials decrease on many plants at the same time due to flooding or general weather situations. Therefore supplementary technologies, such as pumped storage power are still required.

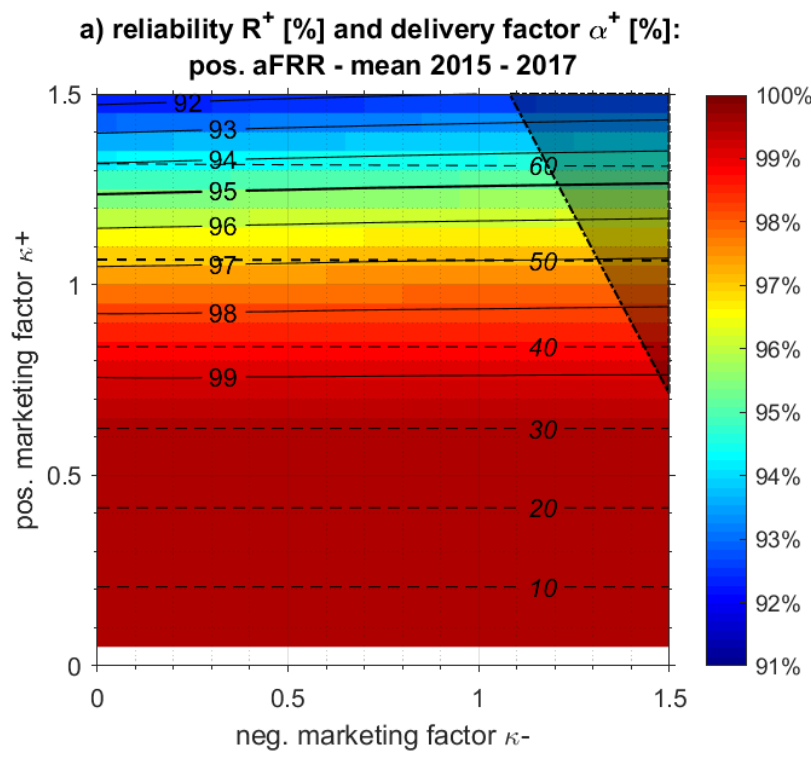

c) reliability $\mathbf{R}^{+}[\%]$ and delivery factor $\alpha^{+}[\%]$ : pos. mFRR - mean 2015 - 2017

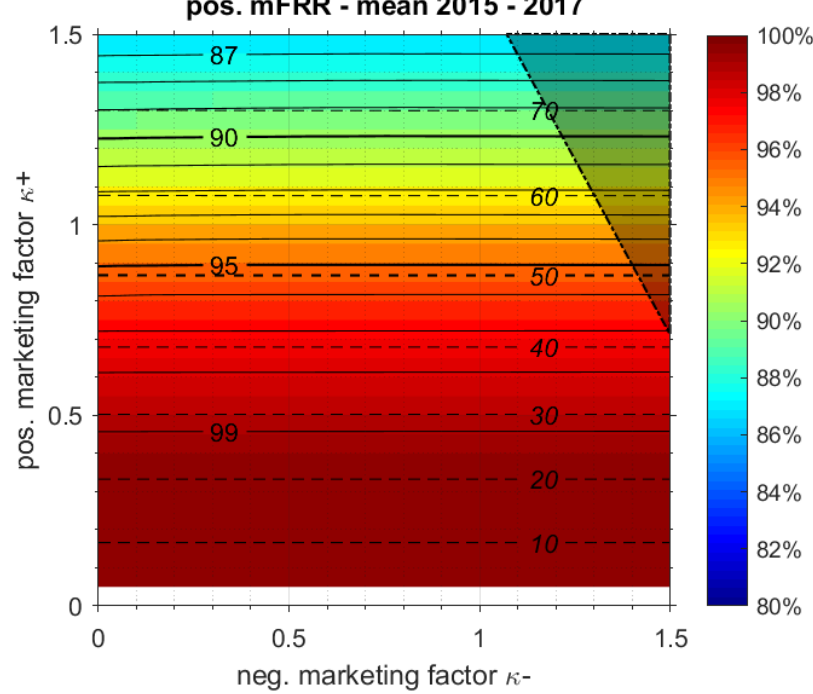

In the case of automatic and manual frequency restoration reserve, the positive and negative balancing energy can be marketed and delivered independently. This leads to an additional degree of freedom reflected by the two independent marketing factors $\kappa^{+}$and $\kappa^{-}$. Fig. 7 shows the achievable reliabilities and delivery factors for the positive and negative, automatic and manual frequency restoration reserve as twodimensional parameter fields over $\kappa^{+}$and $\kappa^{-}$. The reliabilities $R^{+}\left(\kappa^{+} ; \kappa^{-}\right)$and $R^{-}\left(\kappa^{+} ; \kappa^{-}\right)$are shown as a color plot with solid isolines whereas the corresponding delivery factors $\alpha^{+}\left(\kappa^{+} ; \kappa^{-}\right)$and $\alpha^{-}\left(\kappa^{+} ; \kappa^{-}\right)$are printed as dashed isolines.

Apart from the reliability of the negative automatic frequency restoration reserve, the isolines of both the delivery factors $\alpha$ and the reliability $R$ con be considered horizontal for the positive control energy and vertical for the negative control energy in good approximation. This means, that the control power potentials almost exclusively depend on the corresponding marketing factor $\kappa$ whereas they are highly independent of the amount of control energy with the opposite sign. It can be stated

\section{b) reliability $\mathbf{R}^{-}[\%]$ and delivery factor $\alpha^{-}$[\%]:} neg. aFRR - mean 2015 - 2017

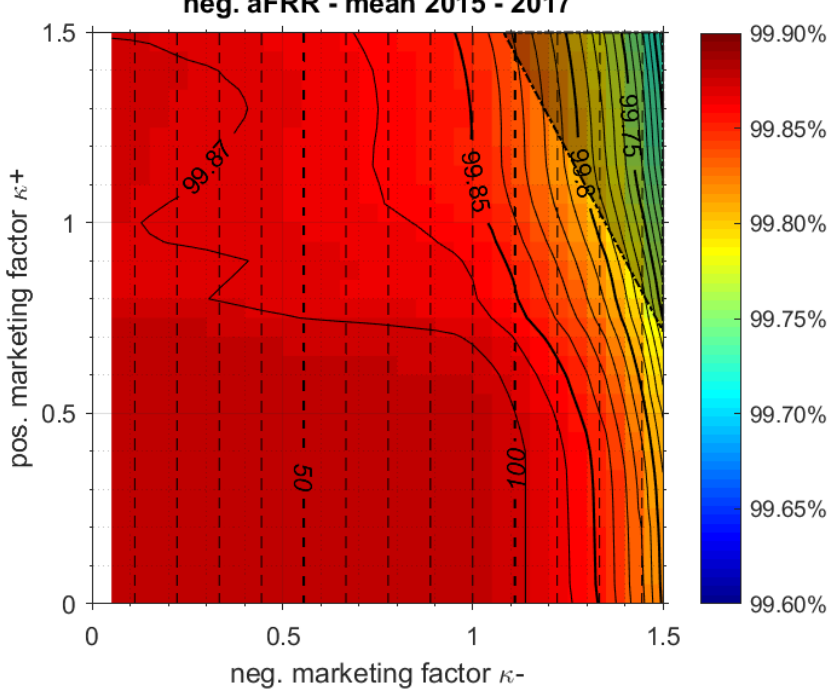

d) reliability $\mathrm{R}^{-}[\%]$ and delivery factor $\alpha^{-}[\%]$ :

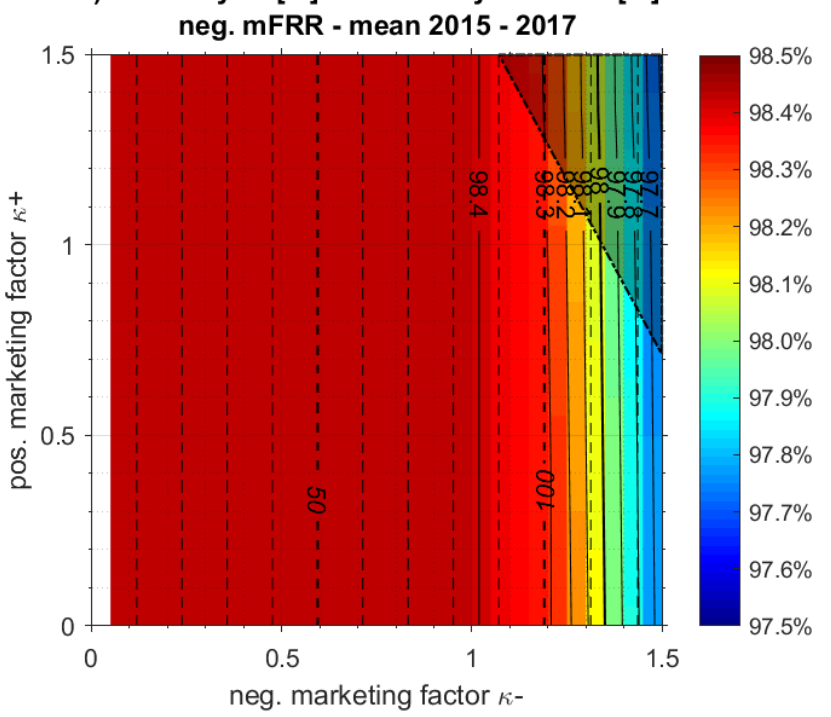

Fig. 7. Average achieved reliabilities $R$ (color plot and solid isolines) and corresponding shares of national demand $\alpha$ (dashed isolines) for the automatic frequency restoration reserve (top) and manual frequency restoration reserve (bottom) in the years 2015-2017. 


$$
\begin{gathered}
\alpha_{C}^{+}=\alpha^{+}\left(\kappa^{+}\right) \quad \alpha_{C}^{-}=\alpha^{-}\left(\kappa^{-}\right) \\
R_{C}^{+}=R^{+}\left(\kappa^{+}\right) \quad R_{m F R R}^{-}=R^{-}\left(\kappa^{+}\right) \\
\text {for } C=\{a F R R ; m F R R\} .
\end{gathered}
$$

Although the total demands of automatic and manual frequency restoration reserve widely differ over a year, the potentials of both types of control energy are generally similar. According to the extrapolated delivery factor $\alpha^{-}$, the national demands for negative automatic and manual frequency restoration reserve can be fully covered with high reliabilities $R^{-}$of around $99.8 \%$ for aFRR and around $98.3 \%$ for $\mathrm{mFRR}$, respectively.

The achievable shares of the national demand $a^{+}$and the corresponding reliabilities $R^{+}$of the positive frequency restoration reserve are noticeably lower than for their negative counterparts. This is mainly due to two reasons. On the one hand, the positive control power is affected by system throttling occurring, when the upstream water level reaches the lower limit and at the same time enhances it. On the other hand, in order to keep the investment costs low, most RORhydroelectric plants have very limited reserves in terms of net power output and maximum flow rate. This narrows the potentials for providing positive control power, especially at times of high natural discharge.

When requesting a minimum average reliability of $95 \%$, during the regarded three-year period $57 \%$ of the national demand of positive automatic and $51 \%$ of the national demand of positive manual frequency restoration reserve can theoretically be covered by the non-swelling RORhydropower in Germany. Since a reasonable increase of reliability can only be achieved when the amount of control energy is significantly decreased, backup capacities are necessary for the positive control energy.

At marketing factors $\kappa>1$, the peak control power offered in a tender is in fact higher than the power reserve estimated by the controller for this period. However, as these estimations have a limited accuracy, this does not necessarily mean, that the maximum reserved control power cannot be delivered. What is more, it is very rare that the full amount of control energy auctioned in the tender is actually activated by the grid operators. For the investigated plant in Bannetze the average necessary positive and negative power reserves for frequency restoration reserve can be expressed for the as an empirical function of $\kappa$ :

$$
\left(\frac{\bar{P}_{C}^{+}}{P_{\max }} ; \frac{\bar{P}_{C}^{-}}{P_{\max }}\right)=\left(\kappa^{+} \cdot b^{+} ; \kappa^{-} \cdot b^{-}\right)
$$

with the factor $b$ :

TABLE III. EMPIRICAL FACTORS FOR THE CALCULATION OF AVERAGE REQUIRED POWER RESERVES FROM THE MARKETING FACTORS $\kappa$.

\begin{tabular}{|l|c|c|}
\hline \multicolumn{3}{|c|}{ Factors for calculation of necessary power reserves } \\
\hline Type of control energy & $\boldsymbol{b}^{+}$ & $\boldsymbol{b}^{-}$ \\
\hline Automatic frequency restoration reserve (aFRR) & $28.4 \%$ & $-53.2 \%$ \\
\hline Manual frequency restoration reserve (mFRR) & $28.9 \%$ & $-52.0 \%$ \\
\hline
\end{tabular}

In case of $\underline{\kappa}=(1 ; 1)$ an average of $80 \%$ of the plant's maximum power output of $700 \mathrm{~kW}$ is required for providing control power. More precisely the plant is needs to retain around $200 \mathrm{~kW}$ for negative control power and around 370
$\mathrm{kW}$ for positive. Hence, in normal conditions, when the maximum plant output is not additionally limited by the maximum flow rate through the waterwheel, the simultaneous production of base power should be in the range of $200 \mathrm{~kW}$ to $700 \mathrm{~kW}-370 \mathrm{~kW}=330 \mathrm{~kW}$. However, when choosing significantly higher marketing factors, the required power reserves can exceed the maximum power generation capacity of the plant. In this case a full delivery of the tendered amount of control power is a priori impossible. In Fig. 7, these "forbidden" states of too high marketing factors are marked with a dash-dotted frame and a shadow.

According to these considerations, the maximum allowed quantity of positive control energy depends on the amount of negative control energy marketed and vice versa. If the national demand of negative automatic frequency restoration reserve shall be completely met by the ROR-hydropower, a maximum of $61.4 \%$ of positive aFRR could still be produced at an average reliability of $93.9 \%$. In this scenario, a marketing factor of $\underline{\kappa}=(1.35 ; 1.15)$ is necessary. In case of the manual frequency restoration reserve, next to the coverage of the full negative demand, $70.0 \%$ of the positive national demand can be covered at a reliability of $89.1 \%$.

Even in the scenarios with the maximum investigated deliveries of control power the amount of simultaneously produced base energy is still more than one magnitude higher. The base power is provided with a reliability of at least $99.8 \%$ in all the scenarios regarded, for all types of control energy and during every year considered.

\section{ENERGY BALANCE AND ECONOMIC EFFICIENCY}

When the plant is operated in the illustrated operation mode, providing control energy and constant base power, the amount of total energy produced is less, than in conventional operation. Firstly, this is due to additional water losses over the weir $\Delta W_{\text {weir }}$. Secondly, the lower average upstream reservoir levels reduce the available head and thus the energy production. In comparison to the conventional operation, serving as a benchmark, the losses lead to an underproduction of total energy $\Delta W_{\Sigma}$ and an underproduction of base power $\Delta W_{B}$. These two values are connected by the formula

$$
\Delta W_{B}=\Delta W_{\Sigma}+W_{C}^{+}+W_{C}^{-} .
$$

For an easier interpretation, these underproductions are related to the energy generation during conventional operation:

$$
\begin{aligned}
\Delta w_{\Sigma} & =\frac{\Delta W_{\Sigma}}{W_{\text {conv }}} \\
\Delta w_{B} & =\frac{\Delta W_{B}}{W_{\text {Bonv }}}
\end{aligned}
$$

$\Delta w_{\Sigma}$ and $\Delta w_{B}$ are shown in Fig. 8 as a parameter field of $\underline{\kappa}=\left(\kappa^{+} ; \kappa^{-}\right)$.

In the years 2015-2017, the relative underproduction of total energy $\Delta w_{\Sigma}$ is between $1.4 \%$ and $8.0 \%$, depending on the marketing factors. It is striking, that the lowest gradients of $\Delta w_{\Sigma}\left(\kappa^{+}, \kappa^{-}=0\right)$ point in the direction of $\kappa^{+}$. Hence, the minimum total losses occur along the line $\kappa^{-}=0$ regardless of the positive marketing factor. This is because the total energy losses are dominated by the additional weir losses. The 
latter are approximately proportional to the amount of negative control energy produced and thus become zero at $\kappa^{-}=0$.

Compared to the additional weir losses the influence of a reduced head on the total underproduction of $\Delta w_{\Sigma}$ is significantly lower. The head-losses increase the higher the amount of positive control power gets. In a smaller extent the head-losses also grow with a decreasing amount of negative control energy. In Fig. 8, this loss mechanism can be identified as the growing total underproduction $\Delta w_{\Sigma}$ along the lines of constant negative marketing factors $\kappa^{-}$. These two loss mechanisms are the reason, why the maximum total energy losses $\Delta w_{\Sigma}$ occur at the point of the highest control power production at $\underline{\kappa}=(1.5 ; 1.5)$.

For the economic viability, the amounts of base power and control energy are more important than the sum of total energy produced. Due to the pay-as-bid auctions, the revenue generate from producing control energy strongly depends on the marketing strategy of each actor. For positive and negative frequency restoration reserve, revenues are generated from the total power reserved for production (power price) and from the amount of control energy actually delivered (energy price). For the base power, only an energy price is granted. This can be a fixed feed-in tariff or the fluctuating energy price on the electricity markets. Although the energy prices of both base power sold directly on the markets and negative frequency restoration reserve can eventually become negative, their average prices remain positive [7].

When looking at the base power (dashed lines), Fig. 8 shows that the underproduction $\Delta w_{\mathrm{B}}$ is getting smaller than the total underproduction $\Delta w_{\Sigma}$ for $W_{C}^{+}<-W_{C}^{-}$. In a scenario of a maximum production of negative automatic frequency restoration reserve and no positive aFRR $(\kappa=(0 ; 1.5))$, the underproduction of base power is even getting zero. Hence, the same amount of power can be marketed on the energy only market as in conventional operation. The negative control energy produced sums up to $6.6 \%$ of the conventional energy harvest. More than that, a power price is granted for $79.7 \%$ of the net output power, equivalent to $560 \mathrm{~kW}$. Consequently, since the same amount of base power sold is accompanied by

rel. underproductions $w_{\Sigma}$ and $w_{B}[\%]$ : aFRR - mean 2015 - 2017

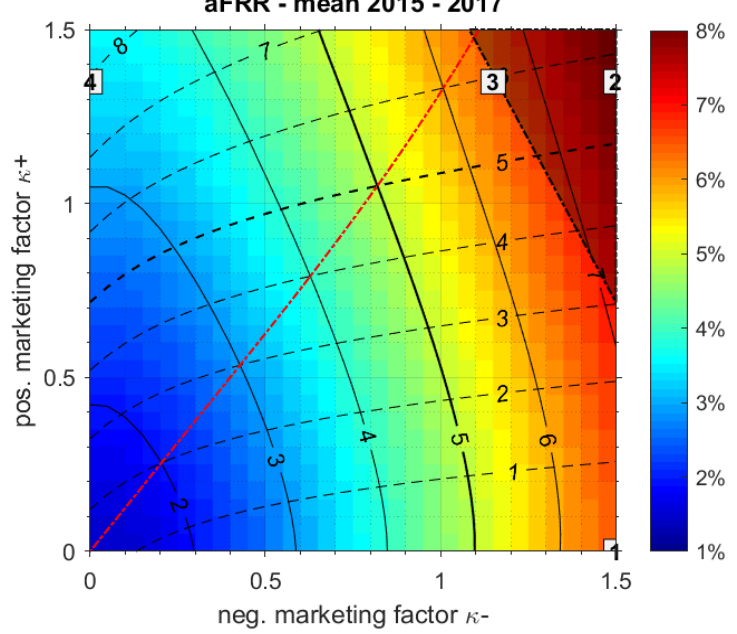

Fig. 8. Average total underproduction $\Delta \mathrm{w}_{\Sigma}$ (color plot and solid isolines) and underproduction of base power $\Delta \mathrm{w}_{\mathrm{B}}$ (dash-dotted isolines) in relation to the conventional energy production for the production of automatic frequency restoration reserve in the years 2015-2017
TABLE IV. MEAN ENERGY PRODUCTION 2015-2017 OF TOTAL ENERGY, BASES POWER AND CONTROL ENERGY AS RELATIVE SHARES OF THE ENERGY HARVEST IN CONVENTIONAL OPERATION FOR DIFFERENT AUTOMATIC FREQUENCY RESTORATION RESERVE SCENARIOS

\begin{tabular}{|l|c|c|c|c|c|c|}
\hline \multicolumn{7}{|c|}{ Energy balance for the delivery of aFRR } \\
\hline Scenario & $\boldsymbol{\kappa}^{+}$ & $\boldsymbol{\kappa}^{-}$ & $\frac{\boldsymbol{W}_{\boldsymbol{\Sigma}}}{\boldsymbol{W}_{\text {conv }}}$ & $\frac{\boldsymbol{W}_{\boldsymbol{B}}}{\boldsymbol{W}_{\text {conv }}}$ & $\frac{\boldsymbol{W}_{\boldsymbol{C}}^{+}}{\boldsymbol{W}_{\text {conv }}}$ & $\frac{\boldsymbol{W}_{\boldsymbol{C}}^{-}}{\boldsymbol{W}_{\text {conv }}}$ \\
\hline 1 & 0.00 & 1.50 & $93.3 \%$ & $100.0 \%$ & $0.0 \%$ & $-6.6 \%$ \\
\hline 2 & 1.35 & 1.50 & $92.2 \%$ & $94.3 \%$ & $4.5 \%$ & $-6.6 \%$ \\
\hline 3 & 1.35 & 1.15 & $93.5 \%$ & $94.0 \%$ & $4.5 \%$ & $-5.1 \%$ \\
\hline
\end{tabular}

additional income from negative control energy the total income in this scenario is higher than in the benchmarking conventional operation. The total energy, base energy and control energy for the scenarios, marked in Fig. 8, are listed in TABLE IV. as relative shares of the energy produced in conventional operation.

In scenario 2 , positive automatic frequency restoration reserve at a minimum reliability of $R^{+}=95 \%$ is produced next to the maximum amount of negative aFRR. In this case of $\underline{\kappa}=(1.35 ; 1.50)$, the necessary power reserves for supplying $100 \%$ of the reserved control power are higher than the maximum plant power of $700 \mathrm{~kW}$. Thus, when there are no backup capacities, the operation point is outside the allowed range. Compared to scenario 1, the total underproduction $\Delta W_{\Sigma}$ is further increased by 1.1 percentage points, mainly because of a decreasing average head. As more positive control energy is generated, the growing balance $W_{C}^{+}+W_{C}^{-}$raises the underproduction of base energy $\Delta W_{B}$ even more to $5.7 \%$, whereas the amount of negative aFRR remains constant. On the other side, the positive automatic frequency restoration reserve amounts $4.5 \%$ of the conventional energy production with a refunded power reserve of $270 \mathrm{~kW}$ or $38.3 \%$ of the maximum output. An analysis of transparency data published in [7] revealed that the energy prices of positive automatic frequency restoration reserve were on average 1.7 times as high as the energy-only prices on the energy exchanges. On the other side the underproduction of base power only accounts to 1.3 times the positive control energy produced. What is more, power prices are granted in addition to the energy prices. Therefore plants receiving no or only low feed-in tariffs can be expected to generate even higher revenues in scenario 2 than in scenario 1 or conventional operation.

Compared to scenario 2 , in scenario 3 the amount of negative automatic frequency restoration reserve is limited in a way that the same amount of positive aFRR is produced, but the total marketed power reserves do not exceed the maximum capacity of the plant. In this case, $61 \%$ of the national demand for positive and $100 \%$ of the national demand for negative automatic frequency restoration reserve can theoretically be covered by the ROR-hydropower. Compared to scenario 2, this reduction in negative control energy leads almost automatically to lower revenues. Firstly, because the growing control energy balance $W_{C}^{+}+W_{C}^{-}$leads to a lower base power production and secondly, because the revenues from the negative aFRR itself reduce. The underproduction of base energy compared to scenario 1 and conventional operation is $6.0 \%$. At the same time, the energy incomes for the negative aFRR decrease by $1.5 \%$ and the refunded power reserve drops 
by $130 \mathrm{~kW}$. In comparison to scenario 1 , however, additional incomes from positive aFRR are generated for an energy amounting $4.5 \%$ of the conventional energy harvest and a power equivalent to $38.3 \%$ of the plant's maximum output. Whether the revenues in scenario 3 are still higher than in conventional operation therefore strongly depends on the price achieved in the power auctions.

In summary, when energy prices are positive the production of the maximum amount of negative automatic frequency restoration reserve with no positive aFRR can securely generate additional revenues. Producing positive and negative aFRR together is only economically feasible, when the additional incomes from control energy can compensate the resulting underproduction of base energy. Since the control energy is auctioned in a pay-as-bid market, the incomes are individual for each market actor and during each tender period. The mean energy price of activated positive automatic frequency restoration reserve in the investigated three year period is approximately $52 \frac{€}{M W h}$, which is around 20 times higher than for negative aFFR. The average positive power price in the same time period is around $4.1 €$ per MW and hour of reservation, which is around 3.5 times the power price for negative aFRR [7]. Therefore, when no higher feedin tariff is granted for the base power, providing positive automatic frequency restoration reserve can be expected to generate additional revenues despite the higher potential costs for providing backup capacities.

\section{SUMMARY}

The simulations conducted on the projected RORhydroelectric plant in Bannetze-Hornbostel showed, that a flexibilization of the upstream reservoir water level of less than $30 \mathrm{~cm}$ reveals significant short-term storage potentials. These potentials allow to schedule the power production one hour before the start of delivery and hold it constant for a period of three hours. Thus, the marketing risks can be reduced. More than that, the storage potentials can be used to produce high amounts of control energy along with the constant base power. These control energy potentials strongly depend on the maximum feasible temporal lowering of the upstream reservoir level. In change, the possibility to increase the water level reduces energy losses caused by water, spilled over the weir. In order to achieve high control energy potentials, the target upstream water level for the investigated plant in Bannetze-Hornbostel was chosen $2 \mathrm{~cm}$ below the maximum and $25 \mathrm{~cm}$ above the minimum acceptable limits. Even though the German ROR-hydropower approximately accounts for only $3 \%$ of the national energy mix, it can be expected to have considerable control energy potentials [8]. When upscaling the potentials to the whole non-swelling ROR-hydropower capacity in Germany, the national demands of frequency containment reserve as well as negative automatic and manual frequency restoration reserve can be fully covered at average reliabilities of $95.0 \%$ for the FCR and $99.8 \%$ and $98.3 \%$ for the aFRR and mFRR, respectively.

For the production of automatic frequency restoration reserve additional energy balances were analysed. In a first scenario with a maximum production of negative aFRR, $79.7 \%$ of the plant's net capacity needs to be reserved for the production of control power. Due to various loss mechanisms, this mode of operation decreases the total plant energy production by $6.7 \%$. However this loss is fully due to the production of negative control energy. Therefore, the same quantity of base power can still be sold. As the prices for both, the power of reserved negative aFRR and for the control energy actually delivered are usually positive, this scenario generates higher incomes than the conventional operation.

The developed operation mode also allows to produce significant amounts of positive automatic and manual frequency restoration reserve. However the potentials are lower than for corresponding negative control energy. When an average reliability of $95 \%$ shall be reached, the German ROR-hydropower can theoretically cover $57 \%$ of the national demand for positive aFFR and $51 \%$ of the demand for positive mFFR, respectively. Higher amounts of control energy are generally possible, but cause a decrease of reliability. This is why backup technologies are indispensable for the investigated peak-to-peak upstream reservoir amplitude of only $27 \mathrm{~cm}$. Despite the need for backups, the production of positive and negative control energy can still be economically feasible. For the automatic frequency restoration reserve, this was investigated in scenario 3. Here, base load underproductions of $6 \%$ were faced by additional positive aFFR incomes composed of energy prices for $4.5 \%$ of the conventional energy production and power prices for $38.3 \%$ of the net output, equivalent to $270 \mathrm{~kW}$. In addition to that, revenues for negative automatic frequency restoration reserve, corresponding to $5.1 \%$ of the energy harvest during conventional operation and $61.1 \%$ of the maximum power, equivalent to $430 \mathrm{~kW}$ are generated. Thus, for plants that do not receive high feed-in tariffs, the combined delivery of positive and negative aFRR can also be expected to yield higher incomes than the conventional plant operation.

\section{ACKNOWLEDGMENT}

The authors thank the foundation Stiftung Nagelschneider for providing the funds for this research project.

\section{DISCLAIMER}

This article was originally published in German under [9].

\section{REFERENCES}

[1] International Renewable Energy Agency, Renewable capacity statistics 2019. Abu Dhabi: IRENA, 2019

[2] L. Hirth, I. Ziegenhagen, und E. Tagesfragen, "Wind, Sonne und Regelleistung“, Energiewirtschaftliche Tagesfragen, Bd. 63, No. 10, p. 2-4, 2013.

[3] M. Brucker, "Wasserkraft als Netzdienstleister am Beispiel der E.ON Wasserkraft $\mathrm{GmbH}^{\text {", }}$ in Wasserkraftprojekte, S. Heimerl, Hrsg. Wiesbaden: Springer Fachmedien Wiesbaden, 2013, p. 129-134.

[4] P. Fischer, B. Stammel, P. Lang, A. Schwab, and B. Cyffka, „Hydrologische Dynamik als Motor für die Renaturierung von Auenhabitaten an der Donau zwischen Neuburg und Ingolstadt“, p. 13.

[5] C. Seidel, „Regelleistung und Kurzzeitspeicherung bei Laufwasserkraftwerken“, VGB PowerTech Journal, No. 9/2015, p. 3441, 2015.

[6] WSA Verden, "Wehr Bannetze“. [Online]. available on: http://www.wsaverden.wsv.de/wasserstrassen/bauwerke/wehre/bannetze/index.html. [accessed: 24-Jan-2020]

[7] Bundesnetzagentur, "SMARD Strommarktdaten“. [Online]. available on: www.smard.de.

[8] ENTSO-E, „Statistical Factsheet 2017“. May 04, 2018.

[9] B. Hase and C. Seidel, „Laufwasserkraftwerke als Anbieter von Regelleistung? Potenziale einer dynamischen Stauhaltung am Beispiel der Forschungswasserkraftanlage Bannetze-Hornbostel“", VGB PowerTech Journal, No. 6/2020, p. 11, 2020 